\title{
Research on the Meaning of Labor and Leisure in the Nature of Man
}

\author{
Pengcheng Li \\ Nanjing University of Aeronautics and Astronautics \\ Nanjing, China \\ Jiangsu Normal University \\ Xuzhou, China
}

\author{
Yanling Mei* \\ Jiangsu Normal University \\ Xuzhou, China \\ *Corresponding Author
}

\begin{abstract}
Labor creates people and leisure makes people who they are. In the nature of human beings, labor shows its full significance. After the work, leisure builds a foundation, silently contributes itself, and moves forward toward the front with the development of labor, contributing to the dynamic link between human's essence and nature. Ultimately, in the unification of labor and leisure, it becomes the essence of human ownership.
\end{abstract}

\section{Keywords-human nature; human attributes; labor; leisure}

\section{INTRODUCTION}

Marx said in his statements that: labor created people; people are animals that make and use tools; actually, man is the sum of all social relations, which reveals the meaning of labor in the creation and development of humans and its status and meaning in the social relations between social development and social relations; which demonstrates the possibility of human's full-scale development provided by the tremendous growth in real productivity; which states that the way of material production decides how to produce and what to produce, the basic conditions of historical social conditions affected by the level of productivity; which demonstrates the development of humans, the historical inevitability of the society and the social consciousness it decides.

\section{THE VALUE OF LABOR AND LEISURE IN HUMAN NATURE}

Marx defines labor as: The first tool of man is his own body, which must be his own possession. Only with the initial product for new production, even if it was just a stone killing animals, the real labor process began. [1]It is pointed out here that labor refers to the purposeful activities in which people use certain production tools, act on objects, and create material wealth and spiritual wealth. Labor is the most basic condition for the existence and development of human society. Man is the only animal that can get rid of pure animal habitus due to labor. Their normal state is adapted to his consciousness and is created by himself. It is not only an activity that exists in reality but also an activity that enables existence to exist. So Marx said that labor created man himself [2], Labor constitutes the essential characteristics of man, labor links the human subjective world with this objective world. And what is corresponding to labor is rest and leisure. Rest gives people more energy to do physical labor, and leisure brings more thought for how to do physical labor. Leisure and labor come together through the long river of people's history. Therefore, there is a saying that leisure is the core of everything.

\section{A. Labor Creates "Leisure"}

In nature, structures such as beehives built by bees, canals carved by beavers and nests made by birds have a lot in common with high-rises and road Bridges built by humans--The architecture is scientific, exquisite, firm and durable. But bees, beavers, birds build houses by instinct, and they construct things only according to the size and needs of the species to which they belong. And the human knows to construct according to any kind of scale and knows to apply the inner scale to the objects everywhere, and to construct according to the rule of beauty. There is an inherent difference between human labor and the instinctive activities of animals [3]. Engels believed that human labor is a purposeful, planned and conscious activity. The results of the activity are preexisting in the human mind. Animals are unconsciously motivated by their instincts and cannot "conceptually" produce the results of their actions in advance. Secondly, human labor is the positive transformation of human beings to the natural world, through which they dominate the natural world and make the mark of their own will in the natural world. The instinct activities of animals are only to adapt to and utilize the nature and change the nature simply by their own existence. Finally, human labor begins with making tools. The manufacture and use of labor tools is an inevitable and universal element of human labor. The "tools" of animals are generally their bodies, and some occasionally use tools that already exist in nature, but they can never make even the roughest stone axes. The manufacture of tools separates man from animals [4]. The essential difference between human beings and animals is the production of life activities, that is, human beings can obtain the objectified unification of themselves and nature, themselves and themselves in work. However, other animals can never do this. People have acquired the two dimensions of cognition and transformation of themselves and the world, and constantly abandon and carry forward themselves and the world in their work, making both of them show a rising trend. And animals can only follow the scale of the species to which they belong, which is the fundamental difference between human beings and animals. It is in this sense that Marx believed that "labor created man 
himself" and that labor is the essence of man. At the same time, labor stimulates new needs. The original passive rest, helpless and natural behavior also gradually turns to conscious and active conduct. People rested in the constructed building, drank water from water source plot, learned the method of food storage, actively draw on the advantages and avoid the disadvantages, make full use of the time to play, and enjoy the sun and the rain. "Leisure" and labor constitute a close relationship, and people's survival and development interweave with each other.

\section{B. The Role of Labor and Leisure in the Formation and Development of Human Beings}

Labor plays a decisive role in the formation of human beings. Engels believed that there was no insurmountable gap between human labor and the instinctive activities of the apes. Labor germinates from, grow and becoming mature from ape's instinct activities. The liberation of the hand and the realization of the independent support and walking of the hind limbs are the decisive steps. The human brain is also gradually formed in the process of changes. People's cooperation and communication are strengthened, and language and advanced thinking are gradually produced. In the same process, human ancestors gradually evolved from using existed tools in nature to learning to make tools, from instinctive labor to real labor. The functions of Engels's labor can be summarized into the following four aspects: the first is that labor promotes the evolution and maturity of human physiological structure. Walking upright, the formation of human hands and the transformation of human body structure are the remolding of human whole frame structure. The harmony of human systems is the result of evolutionary selection. Changes in the human brain and the formation of language centers are the result of changes stimulated in various kinds of demand in the course of labor. So, labor creates man himself. Secondly, labor creates material conditions for human survival, and people obtain basic living conditions for food, clothing, housing and transportation through labor. Third, the labor process strengthens the cooperation and exchanges between people. In the conquest and transformation to the natural world, it is difficult for one person to achieve. It requires cooperation and communication from others. The normal communication and cooperation strengthen the individual connection, strengthen the communication between groups and promote the development of social relations. Fourthly, labor produces human culture, records and inherits people's experience of conscious activities, and gradually improves the platform for human survival and development. In the primary stage of social development, people work hard and enjoy the fruits of their labor. Engels said in his statement that labor is the basis for the creation, development and promotion of human being and the improvement of individual ability and level. With the improvement of the ability and level of people's labor, material living materials became abundant, the private ownership emerges, the differences of class emerge, and the role of labor have also changed. It has become an important means for people to accumulate and possess wealth. The people who enjoy the fruits of labor and labor have changed. There is also a division between the mental labor and the physical labor. But no one can live without labor. Labor has led to the formation of human brain, the generation of language, the optimization of body, the transformation of human communication forms, the formation and development of consciousness, and increases the social existence platform. "Leisure" in the development of the base station gradually increased its position, and it also serves for its improvement.

\section{The Value of Labor and Leisure to the Formation and Development of Human Society}

Labor supports the existence and the development of human society. In this process, with the transformation of production mode, the refinement of social division of labor, labor has also changed, which is mainly reflected on workers. The king of labor is mainly manual labor instead of mental labor, direct labor instead of indirect labor, tangible labor instead of intangible labor, material labor instead of spiritual labor. The root of this transformation lies in the integration of people's accumulated wisdom in labor, the improvement of people's labor ability, the formation of relevant culture, and the reaction of the formed wisdom to the labor. The current development trend of labor is the spatial separation between laborers and labor, namely laborers can also carry out production activities outside the production field, which separates the time between the labor effort and the labor realization. The labor tool intervenes between worker and labor object, which changes the effect between labor effort and labor realization. The advanced degree of labor tools is the basic sign of the development of human society.

Labor created people. People obtain the material conditions for survival in labor and they also enjoy the labor income and achievements. Engels described the working and living conditions of human beings in the "primitive age" in his work private ownership of the family and the origin of the state: living in nature, no guarantee for food, hunting is one of the regular labor activities, passive usage is the principle way and active creation is the affiliated one. Leisure and Labor are in a low-level state of unity, which is a state of instinct and playfulness. Or in the confusion and helplessness of the hope, they form a prayer for the mysterious protection in the religious form. With the improvement of the ability and the level of the active transformation of nature, the emergence of the personal ownership, private properties have become the active activities and properties of the personals, namely the labor [5]. With the private ownership of labor and the different ownerships of labor, labor changes. People who own their own labor and also own part of others' labor enjoy their own labor and enjoy the appreciation of others' labor. The group with such qualifications is what we call the slave-owner class, the landlord class and the bourgeoisie. The slave class, the peasant class, and the proletariat class are those who possess part of their labor, that is, those who maintain their lives by selling their labor. In such a class society, leisure and labor are separated, even are mutually exclusive and antagonistic. From the perspective of workers, leisure is the process of relieving fatigue between work hours, or the process of "rest", which is a helpless instinctive demand and a necessary process. From the perspective of higher social members, leisure is a process to meet their increasing social needs, maintain and consolidate their dominant position and make themselves into the class 
with abundant leisure. It is the process of perfecting oneself by meditating on the problems of truth, goodness and beauty. Therefore, in class society, leisure is a symbol of status and wealth and power. The slave's lack of "leisure" indicated the ownership of leisure and also divided two camps. The difference between the two camps is that some people enjoy leisure, some people expect leisure, or that some people work, and some people enjoy work.

\section{THE VALUE OF LABOR AND LEISURE IN HUMAN NATURE}

Marx's view on human nature holds that "man has two attributes, one is his natural attribute and the other is his social attribute". The so-called natural attribute refers to the existence of human body and its characteristics, which is the basis of human existence. The most fundamental characteristic of human is his sociality, and the social attribute of human is the unique characteristic that people show when they have a relationship with the things around them.

\section{A. The Expression of the Meaning of Labor and Leisure in People's Natural Attributes}

"Engels said in the Anti-Duhring that: "The fact that man comes from the animal kingdom has determined that man can never get rid of his animal nature completely. So the problem is always to get rid of it to what extent, the extent of the difference between animal nature and human nature [6]. The animal nature mentioned here refers to the biological nature of human beings, such as eating, drinking, exertion, sleeping, and sex (reproduction), and biological factors such as ferocity, greed, possession, desire, selfishness, favoritism etc. This natural attribute of human is the most basic physiological condition and material basis for the formation and development of human nature and is the prerequisite and element for the formation of human nature. After people leave the animal kingdom, they do not completely abandon their animal nature. On the contrary, the nature is still retained and manifested in people. Marx and Engels did not reject the animality of man. The key is how much they abandon them in the process of becoming human beings. As a matter of fact, some creatures did not abandon them after they becoming humans but should exist with them as a necessity. For example, people's physical instincts, such as eating, drinking, exertion, sleeping, and sex (reproduction), are fundamental to human existence. In this regard, Marx said in the German ideology that we must ensure the perquisite of all the survival of humans, which is the first perquisite of the history is that people create history to live. And to survive, humans need clothes, food, shelters and other stuff. Therefore, the first historical activity was the production of the materials needed to meet these needs, namely the production of material itself [7]. Restricted by human body organizations, people must produce materials and carry out it in a certain form. The needs of people's body, which is pure and original, are the primary motivations to promoting social relations and practical activities of people. Nietzsche, Feuerbach, Paul Ji Gregorian, Bergson, Edward o Wilson all affirmed the significance of human nature. And they put this natural attribute to be human essential attributes, and confuse peoples as animals, which is definitely wrong.
Maslow divides people's natural attributes into all the attributes they have according to their physiological, security, belonging, love, respect and self-realization. It believes that the lower the level is, the stronger the human biology is; the higher the level is, the farther away it is from animal nature, the closer it is to human social nature. Labor and leisure make the human biology get sufficient development, but also make the human gradually far away from the animal attribute.

\section{B. Expression of the Meaning of Labor and Leisure in the Formation of People's Social Attributes}

Engels's view that the essence of man in its reality is the sum total of all social relations tells us that humans have both natural attributes and social attributes, and the sociality of human is the utmost characteristics. Natural attribute is the foundation of human existence, and social attribute is the essential attribute of human. The social attribute of human refers to the characteristic that people form a certain relationship with each other, jointly engage in productive activities and all other social activities, which is a sign of the difference between human beings and animals. A person's sociality is determined by the certain social relations he is in. This kind of social relation includes production relations, political relations, ethical relations, ideological relations, legal relations, etc. The sum of these social relations is the social attribute of human beings. These relationships play a decisive role in the formation and development of human beings. As an individual, if he does not have certain relations with others, engage in productive activities, or live a solitary life, he cannot become a human being or survive. People's various kinds of activities are carried out in a certain society. The more human history develops, the stronger the social nature of labor is. The specific productive labor that everybody is engaged in is part of the total production of the society. Each link of every production activity is closely connected with the chain of total social production. Productive relation is the main relation among social relations, it is the basic primitive relation that decides all relations. The economic, cultural and political development of human society on the basis of production relations; the legal, moral, religious and other institutional norms that formed on this basis, and the social interaction between industries caused by social division of labor all reflect the essence of human beings from different aspects and levels. Man produces products through labor, and produces relations of productive behavior, relations between man and his products, and relations between man and others. Production itself is based on personal interaction, which is in turn determined by production. The productivity, division of labor and the development degree of internal communication influence the communication relations among different ethnic groups. The development level of productivity is reflected in the development degree of division of labor. Different stages of division of labor development represent different forms of ownership. Each stage of the division of labor determines the relationship between individuals and labor materials, tools and products [8]. Division of labor caused the separation between business and agriculture, urban and rural, the commerce and industry, which affected the national inside and outside. It also enlarged the scope of communication, formed a new social relationship, and led to the emergence of private property. 
Marx said that the productive forces determine the productive relations, and the productive relations react on the productive forces. He also said that social relations are constantly updated in the interlacing of productive forces and productive relations, and people are developing in the ever-renewing social relations.

For labor and social relations, human labor is the premise and basis of the sum total of all social relations. The sum of social relations is the vivid life of man. Social relations are not external relations; they are the conditions of an individual's life and are created by such independent activities. Labor belongs to human beings. Labor creates and determines social relations. Human beings exist in social relations. A certain social relationship is a specific historical form of human activities, and its nature and change are determined by the nature and level of practical activities. Without practice, it is impossible to produce social relations.

Of course, the natural attribute and social attribute of human are not two isolated existences but are unified in the reality of human existence and melt in the work and leisure. The natural attribute of human is the material basis of human social attribute, which maintains human existence. They are attributes that have been socialized. The two attributes depend on each other, influence each other, and transform each other. The natural attribute of human has the sociality that inherits from the social history result. People reflect their essence in their practices of reforming the objective material world. They develop two kinds of relations in practice: one is the relationship between man and nature, the other is the relationship between man and man. The relationship between man and nature is more about natural attribute. In the process of transforming the objective world, people satisfy their physiological needs of eating, wearing and living. When people have relations with each other, they reflect more of their social attributes, which is fully reflected in people's social production and social communication. As the sum total of all social relations, human nature includes the relationship between people and the relationship between people and nature with social significance. Some people's views on human essence and human nature are paranoid about natural attributes, which equate human beings with wild animals. Some people are paranoid about human sociality and then regard it as a metaphysical abstraction. Others have replaced human nature with purely the class diversifications. These are all one-sided understandings of human essence and human nature. Human nature is the unity of natural and social attributes. Therefore, vigorously developing the social productive forces and improving the economic construction are necessary to guarantee the physical and material needs from human natural attributes. Secondly, considering the social development of human beings, we should promote the construction of socialist spiritual civilization and promote the development of human beings in the harmonious development of social relations. Human physiological practice, psychological practice and social practice blend into various social relations of different natures and assume different social roles in these social relations. Also, they use various activity tools to achieve the corresponding development goals and tasks. The internal world of man is connected with the external world in the alternation of social relations.

\section{CONCLUSION}

As an important thrust of human social development, the economic foundation is determined by the productivity of a certain stage of social development and is an important component of the productive relationship. In essence, it is a basic economic system in a certain stage of social development and an institutionalized material social relationship. The nature of economic foundation determines the nature of the superstructure. The superstructure is an ideology and its corresponding system, organization and facilities based on a certain economic foundation. The superstructure serves the formation and consolidation of its economic foundation and maintains its dominant position in society. Just like the contradictory movement between productivity and production relations, when the superstructure is suitable for the economic foundation required by the development of the productive forces, it will promote the development of the society; otherwise it will hinder the development of the society.

Look back on the coordinated development of productivity and production relations, there is an emergence of status and class caused by the inner division of labor. Due to the difference in economic foundation, one's social status and political rights presented the hierarchy and difference, which also leads to the imbalance of human development. Therefore, it begins to express the difference between labor and leisure. Some people enjoy leisure and some people serve for the leisure. When the two are irreconcilable, the state emerges as a machine of violence to mediate and maintain the current imbalance. For leisure, it's local and hierarchical. And the leisure culture formed also has the opposite aspects of leisure and labor. In the future, there will be a highly developed society, in which work and leisure are unified, people's selfaction and freedom are unified, and people truly possess all their essence.

\section{REFERENCES}

[1] Marx and Engels, German Ideology, People's Publishing House, 2008.2

[2] Marx and Engels, Selected Works of Marx and Engels, vol. 3, People's Publishing House, p. 140, 1995

[3] Marx, German Ideology, People's Publishing House, 3rd edition in 2008

[4] Marx, 1844 Manuscripts of Economic and Philosophy, People's Publishing House 2008.5 printing P73

[5] Complete Works of Marx and Engels, vol. 47, People's Publishing House, 1979, p. 105. 